\title{
Local Fascio-Cutaneous Flaps for Skin Cover after Large Mastectomies for Locally Advanced Breast Cancer - An Indian Perspective
}

\author{
Hemant Goyal ${ }^{1}$, Ruchika Agarwal ${ }^{2}$ \\ ${ }^{1}$ Assistant Professor, Department of Surgery, F.H. Medical College and Hospital, Near Railway Over Bridge, Etmadpur, Agra, India, ${ }^{2}$ Assistant Professor, \\ Department of Obstetrics and Gynaecology, F.H. Medical College and Hospital, Near Railway Over Bridge, Etmadpur, Agra, India.
}

\section{Abstract}

Background: Many patients in India still present with locally-extensive breast cancer to the general surgeon. Surgical ablation for such tumours results in large chest wall defects management of which becomes difficult in absence of surgical oncologist- plastic surgeon team - as is the case in large parts of the country. The purpose of this article is to present simple local fascio-cutaneous flaps which can be done by general surgeons. Subjects and Methods: Among 8 local flaps, 5 were laterally based thoraco-abdominal (TA) flaps, and 3 were medially based thoraco-epigastric (TE) flaps. Clinical outcomes were compared including complications, the need for a secondary surgical intervention, and the timing of adjuvant therapy. Results: The mean defect size was $410.6 \mathrm{~cm} 2$ (range, 140-720 cm2). One case of wound dehiscence $(12.5 \%)$ was noted in the lateral based (TE) flap group. All patients survived more than 1 year without any local recurrence or delay in adjuvant treatment. Conclusion: Local fascio-cutaneous flaps are a viable option to treat large chest wall defects after the excision of locally advanced breast cancer. They are simple, robust and can be performed easily by general surgeons.

Keywords: Breast cancer, Fascio-cutaneous flaps, Chest wall reconstruction.

Corresponding Author: Dr.Ruchika Agarwal, Assistant Professor, Department of Obstetrics and Gynaecology, F.H. Medical College and Hospital, Near Railway Over Bridge, Etmadpur, Agra, India.

Received: May 2019

Accepted: June 2019

\section{Introduction}

Huge locally advanced breast cancers frequently large fungating masses are still a reality in our country[Figure 1]. Large size may be due to lack of treatment or as is often the case progressive disease due to incomplete or erratic treatment often due to financial constraints. Surgical ablation leads to immediate improvement in quality of life due leads to large skin defects management of which becomes difficult in absence of surgical oncologist- plastic surgeon team - as is the case in large parts of the country. Another concern with surgical treatment is delay in systemic adjuvant treatment. a variety of techniques are available for covering any large chest wall defects, including skin grafts, local skin or fascio-cutaneous flaps, omental flaps, and myocutaneous flaps such as pectoralis major, rectus abdominis, latissimusdorsi, and external oblique flaps. ${ }^{[1-7]}$ Most of them apart from skin grafts and local facio-cutaneous flaps require a plastic surgeon or a surgeon trained in oncoplasty. Such a scenario is often lacking in majority of centres where these poor patients present. Skin grafts are not suitable as almost all these patients are candidates for radiotherapy. ${ }^{[1,8]}$ Skin flaps are usually preferred to myocutaneous flaps because of their relative simplicity and comparable results. ${ }^{[2,8]} \mathrm{We}$ describe our use of local skin flaps to cover skin defects after the surgical ablation of locally advanced breast cancer. These flaps are simple, quick, robust and have a short learning curve and can be performed by all general surgeons even in low resource setting. The purpose of this study was to share our experiences using local fascio-cutaneous flaps.

\section{Subjects and Methods}

All mastectomies performed in a single unit between August 2014 and April 2019 were retrospectively reviewed. Eight patients were identified who underwent local fasciocutaneous flaps for chest wall reconstruction (Table 1). Chart review was performed to obtain data on sex, age, diagnosis, oncological status, adjuvant therapy, location and size of the defects, and complications.

\section{Surgical techniques}

Initially every attempt is made to close the defect primarily by mobilizing skin flaps superiorly and inferiorly - from over the clavicle to up to umbilicus without additional incisions. The plane of dissection is prefascial, and perforators from the epigastric and intercostal vessels are preserved whenever possible. The created cephalic and caudal flaps are sutured together, leaving a horizontal scar. If 
excessive tension develops during closure, a local fasciocutaneous flap is used. Two types are described - one laterally based or thoraco-abdominal (TA) flap and the other medially based or thoraco-epigastric flap (TE).

\begin{tabular}{|c|c|c|c|c|c|c|c|c|}
\hline Patient & Age & Defect & $\begin{array}{l}\text { Operation } \\
\text { method }\end{array}$ & Pathology & Start of & Stage & Mastectomy & $\begin{array}{l}\text { Survival/Com- } \\
\text { plication }\end{array}$ \\
\hline 2 & 42 & $30 \times 20$ & Lateral based & IDC & POD 28 & T4N1M1 & 2600 & $1 \mathrm{yr} / \mathrm{WD}$ \\
\hline 3 & 40 & $15 \times 12$ & Medial based & Fung-IDC & POD 21 & T4N1M1 & 1000.0 & 4Yr/None \\
\hline 4 & 67 & $18 \times 20$ & Medial based & Fung-IDC & POD24 & T4N1M1 & 500 & $2 \mathrm{Yr} / \mathrm{NONE}$ \\
\hline 6 & 35 & $30 \times 24$ & Lateral based & Phylloides & - & - & 1500.0 & NA/None \\
\hline 7 & 45 & $17 \times 20$ & Lateral based & Rec IDC & POD 30 & T4N0M0 & 1200.0 & 2yr/None \\
\hline 8 & $62 / \mathrm{M}$ & $25 \times 17$ & Lateral based & $\begin{array}{l}\text { Carcino- } \\
\text { sarcoma }\end{array}$ & POD 20 & T4N0M0 & 1100.0 & NA/None \\
\hline
\end{tabular}

IDC, intraductal carcinoma; POD, postoperative day; TNM, tumor, node, metastasis;WD Wound Dehiscence; NA - Surviving till date.

\section{TA flap - Laterally based}

The TA flap is basically a rotation-advancement flap that uses the lateral intercostals, subcostal, and lumbar arteries. An incision is made at the midline of the abdomen all the way down to the umbilicus, and further dissection proceeds inferiorly and laterally across a prefascial plane. The pedicle of this flap can be identified at the medial edge of the external oblique muscle and preserved. The flap is rotated clockwise for left chest wall defects, or counterclockwise for right chest wall defects [Figure 2-4]. This flap is usually indicated when a higher portion of the defect lies medial, or a large amount of medial advancement is required.

\section{TE flap - Medially Based}

The TE flap is like a mirror image of the TA flap and uses perforators from the superior epigastric artery. The incision starts at the lower lateral angle of the defect and curves laterally down along the mid-axillary line. Dissection continues medially and inferiorly, thereby preserving the superior epigastric perforators that pierce the rectus abdominis fascia [Figure 5-9]. This flap is usually indicated when the required medial advancement is relatively small and a higher portion of the defect lies laterally toward the axilla.

\section{Results}

Between August 2014 and April 2019, 8 local flaps were performed to cover chest wall defects after surgical ablation for locally advanced breast cancer. Among 8 patients, 7 were female and the mean age was 45.8 years (range, 26-67 years). Six patients were diagnosed with invasive ductal carcinoma of the breast, 1 with an invasive phyllodes tumor, and 1 with a carcino-sarcoma of breast. The mean follow-up period was 22 months (range, 2-48 months). The mean specimen weight was $1162.5 \mathrm{~g}$ (range, 500-2600 g; median, $1050 \mathrm{~g}$ ). The mean defect size was $410.6 \mathrm{~cm} 2$ (range, 140$720 \mathrm{~cm} 2)$. One case of wound dehiscence $(12.5 \%)$ was noted in the lateral based (TE) flap group. It required resuturing and healed in less than 3 weeks.

Adjuvant chemotherapy and/or radiation were indicated for 6 patients. Adjuvant therapy was initiated after an average of 23.8 postoperative days.

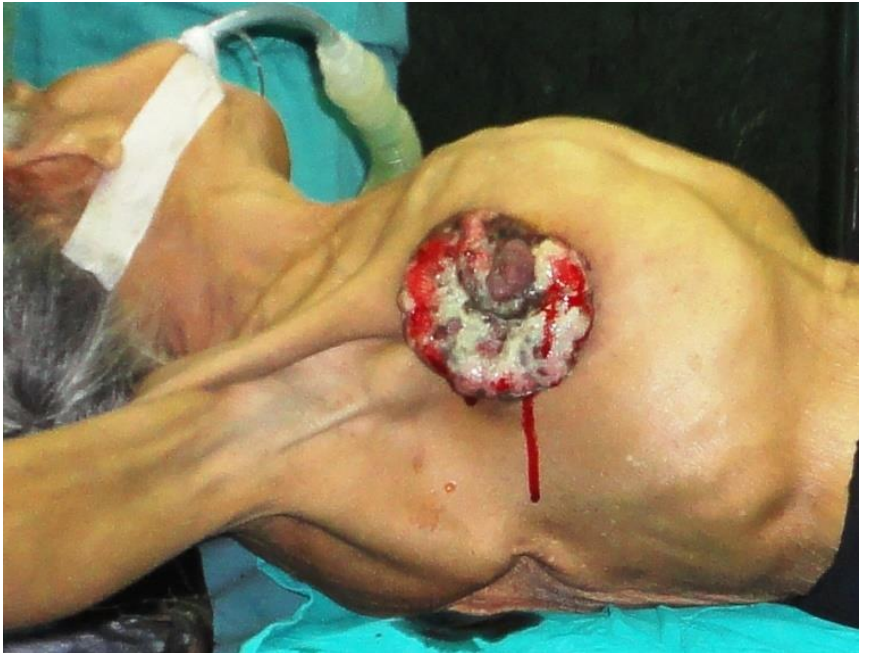

Figure 1: Large bleeding tumour occupying whole breast in thin woman

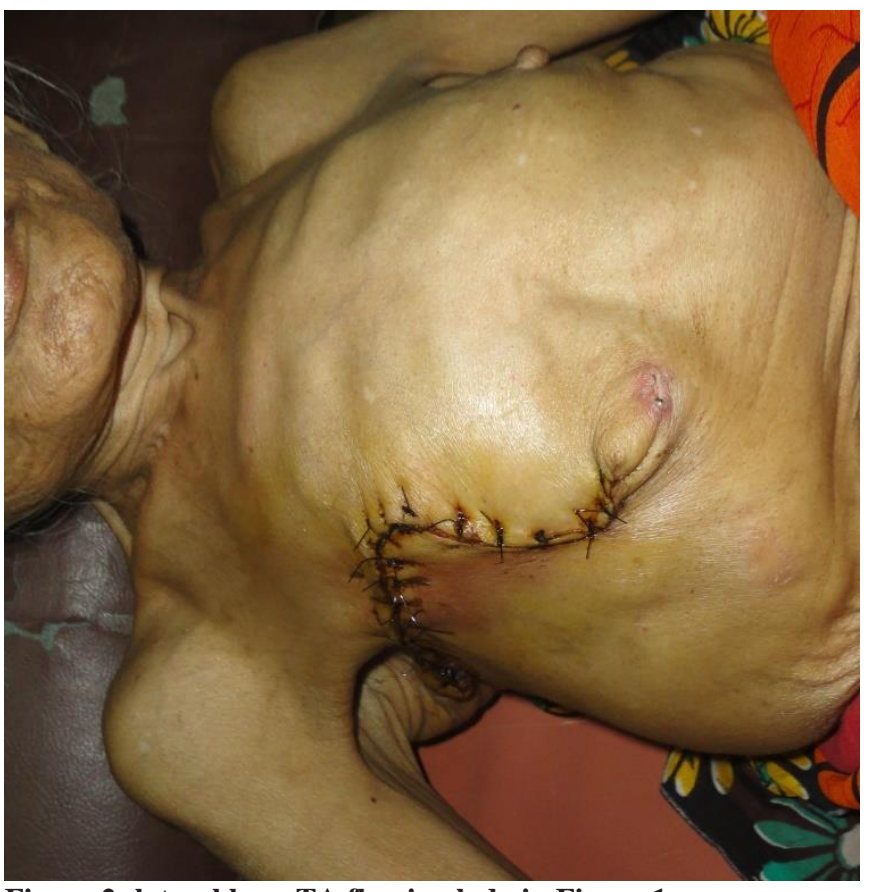

Figure 2: lateral base TA flap in lady in Figure 1. 


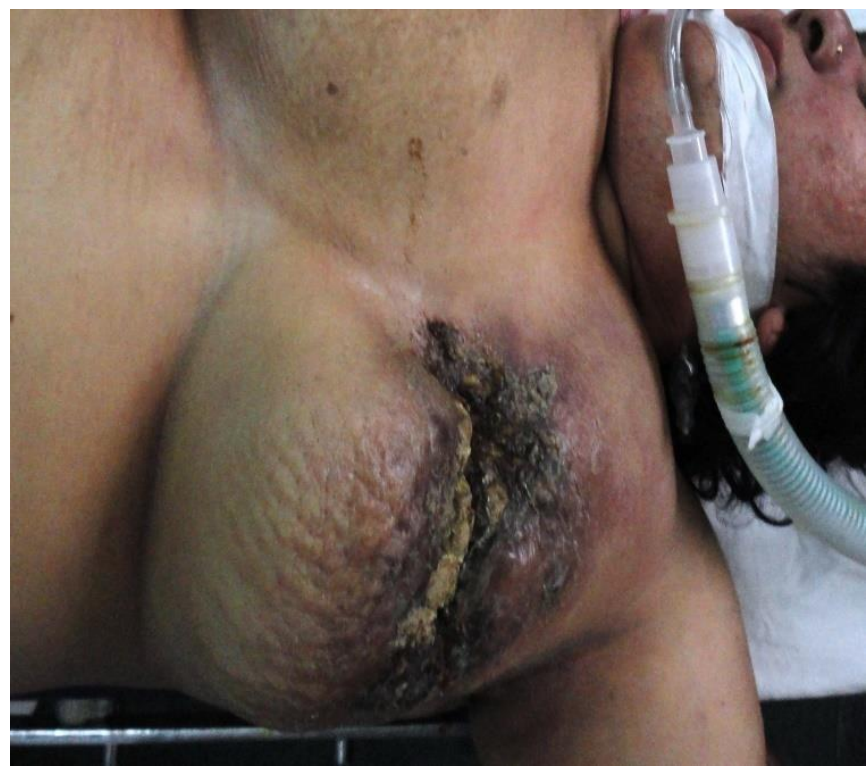

Figure 3: large fungatingtumour after 6 cycles NACT

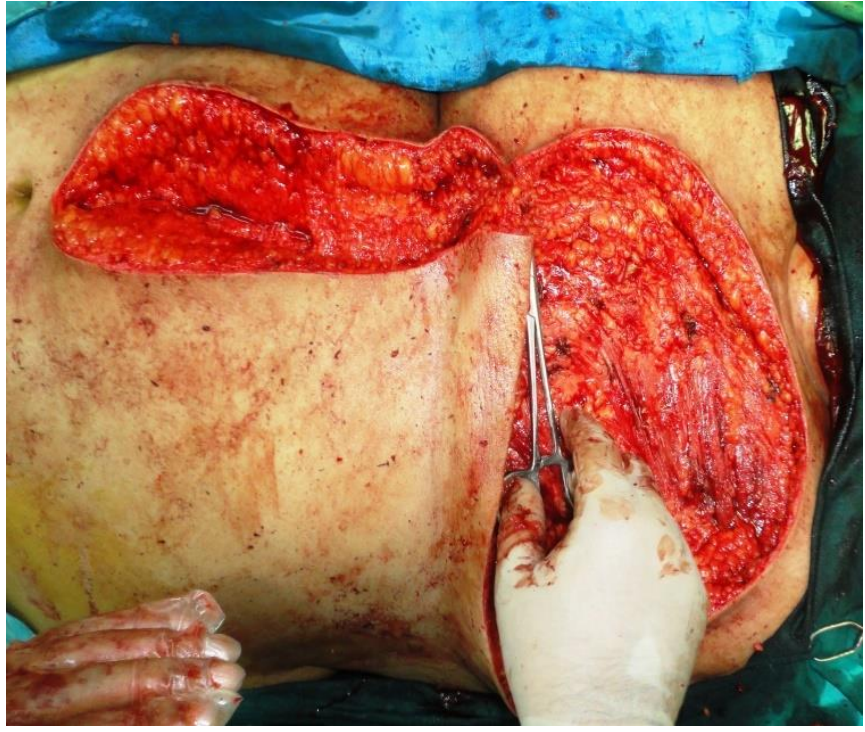

Figure 4: lateral based TA flap in lady in Figure 3.

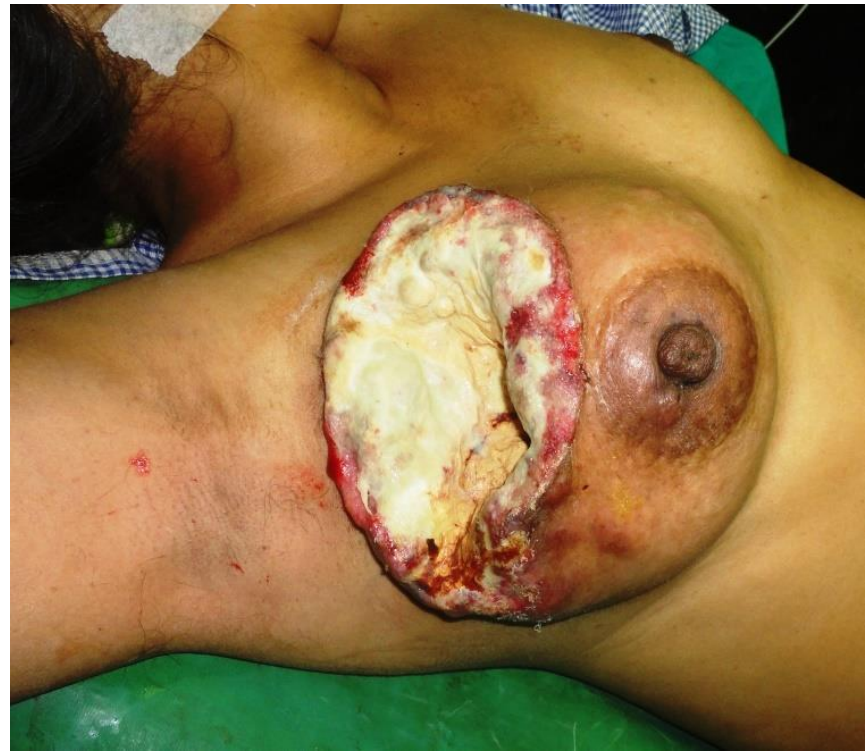

Figure 5: large foul smelling deep crater in lady after NACT

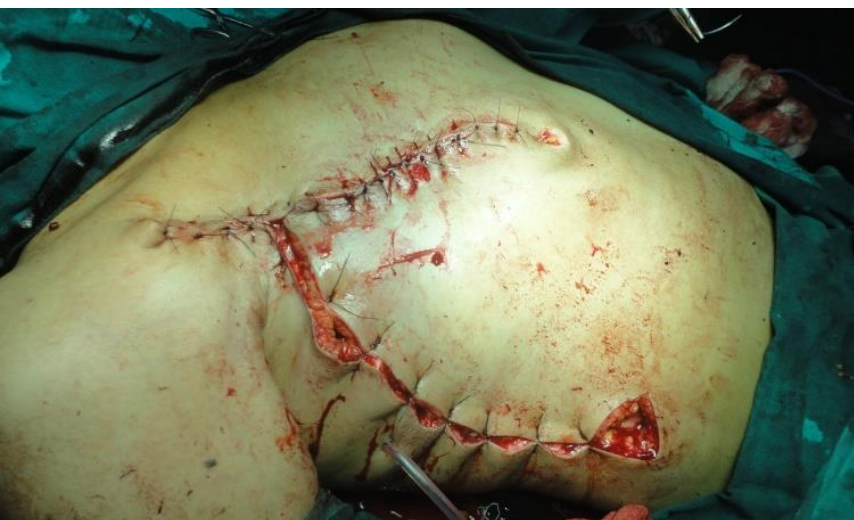

Figure 6:Medial based TE flap closure in lady of Figure 5.

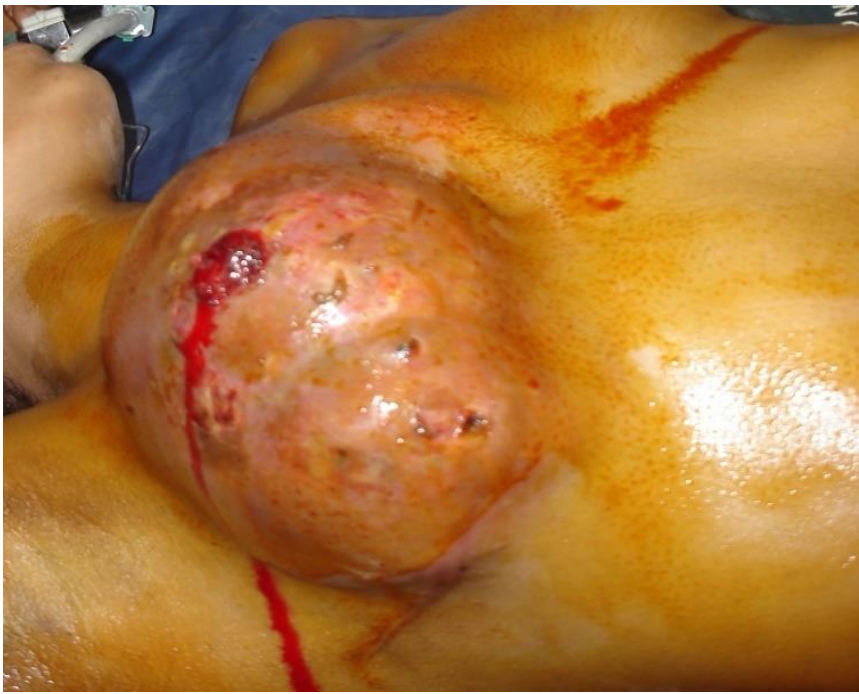

Figure 7: large phylloidestumour

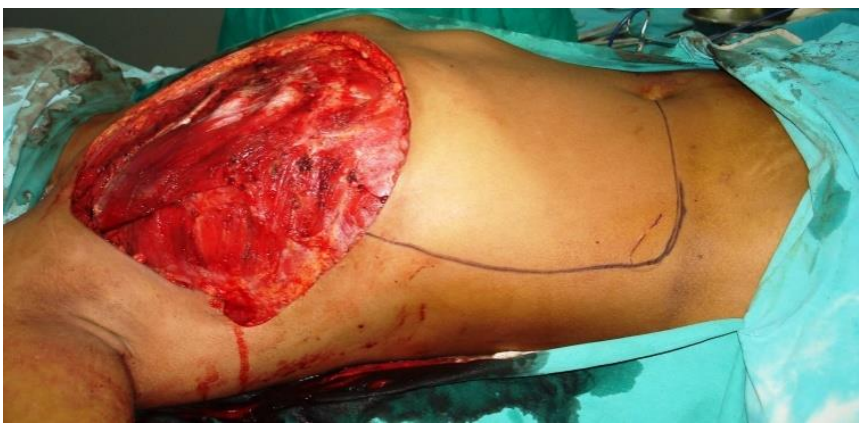

Figure 8: defect after resection inFigure 7 with flap planning

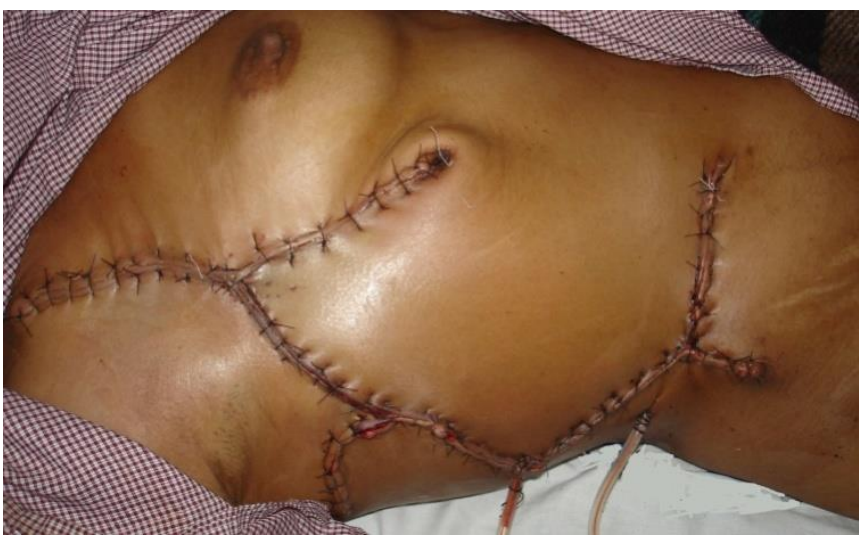

Figure 9: closure with medial based TE flap in Figure 7,8. 


\section{Discussion}

With the increasing awareness, screening programs, advances in systemic treatments it is becoming less common to see large breast tumours with fungation and foul smell. However surgeons outside the major oncologic centres still encounter such patients. Also many patients after failed treatments present in this way. Very often such patients have exhausted their meager resources and just want some palliation. Surgical ablation of such tumours present a challenge to the general surgeon and the problem is compounded by absence of oncoplastic expertise. A lot of justified focus is on breast reconstruction nowadays but attention is also needed for reconstructing large chest wall defects following a so-called "toilet mastectomy". ${ }^{[9,10]}$ A variety of locoregional tissue transfers have been introduced, and the common goal is to provide early wound healing and a low risk of total flap failure. ${ }^{[1-4,7,8]}$

The lateral based TA flap uses the skin, subcutaneous tissue of the anterior abdominal wall, and the direct perforating vessels of the segmental arteries that arise from the subcostal, intercostals, and lumbar arteries. ${ }^{[2,3]}$ Epigastric perforators can also be pre-served whenever possible. Deo et al. ${ }^{[2]}$ reported that this flap is better than the myocutaneous flap in terms of mean blood loss, operating time, and length of hospital stay, and Persichetti et al ${ }^{[3]}$ have described using extended TA flaps to repair extensive defects $\leq 600 \mathrm{~cm} 2$. We believe perfusion to the TA flap is relatively robust, but the main drawback of this flap is the vertical midline scar.

The medial based TE flap is mainly supplied by perforators from the superior epigastric arteries..$^{[1,4,5]}$ Using a midaxillary incision, the vertical scar can be concealed when the arm is in a neutral position. The large rotation-advancement flap design is hemodynamically weak, as reported by Baroudi et $a,^{[11]}$ and behaves more like a random flap. However we did not encounter any flap necrosis in the 3 medial based flaps in our patients. This may be because the distal portion of this flap usually goes around the axillary area, where some redundancy in the local tissues allows relatively less closing tension.
All these patients had survival greater than one year. None developed a local recurrence. This is a major relief to these patients who are battling large fungating foul smelling tumours.

\section{Conclusion}

The two types of local skin flap described here could be applied to locally advanced breast cancer surgeries that leave a large chest wall defect. These are particularly relevant to Indian setting where there is huge mismatch in available high standard oncological facilities and their demand in an affordable and accessible manner.

\section{References}

1. Skoracki RJ, Chang DW. Reconstruction of the chest wall and thorax. J Surg Oncol 2006;94:455-65.

2. Deo SV, Purkayastha J, Shukla NK, et al. Myocutaneous versus thoraco-abdominal flap cover for soft tissue defects following surgery for locally advanced and recurrent breast can-cer. J SurgOncol 2003;83:31-5.

3. Persichetti P, Tenna S, Cagli B, et al. Extended cutaneous 'thoracoabdominal' flap for large chest wall reconstruction AnnPlastSurg 2006;57:177-83.

4. Matros E, Disa JJ. Uncommon flaps for chest wall reconstruction. SeminPlastSurg 2011;25:55-9.

5. Rivas B, Carrillo JF, Escobar G. Reconstructive management of advanced breast cancer. Ann PlastSurg 2001;47: 234-9.

6. Foster RD, Hansen SL, Esserman LJ, et al. Safety of immediate transverse rectus abdominismyocutaneous breast reconstruction for patients with locally advanced disease. Arch Surg 2005;140:196-8.

7. Micali E, Carramaschi FR. Extended V-Y latissimusdorsimusculocutaneous flap for anterior chest wall reconstruction. PlastReconstrSurg 2001;107:1382-90.

8. Leinster SJ, Webster DJ. Thoraco-abdominal and thoraco-epigastric flaps: alternatives to skin grafting after mastectomy. ClinOncol 1982;8:145-8.

9. Lee MC, Newman LA. Management of patients with locally advanced breast cancer. SurgClin North Am 2007;87:379-98.

10. McCraw JB, Bostwick J 3rd, Horton CE. Methods of soft tissue coverage for the mastectomy defect. ClinPlastSurg 1979;6:57-69.

11. Baroudi R, Pinotti JA, Keppke EM. A transverse thoracoab-dominal skin flap for closure after radical mastectomy. Plast Reconstr Surg 1978;61:547-54.

Copyright: (C) the author(s), 2019. It is an open-access article distributed under the terms of the Creative Commons Attribution License (CC BY 4.0), which permits authors to retain ownership of the copyright for their content, and allow anyone to download, reuse, reprint, modify, distribute and/or copy the content as long as the original authors and source are cited.

How to cite this article: Goyal H, Agarwal R. Local Fascio-Cutaneous Flaps for Skin Cover after Large Mastectomies for Locally Advanced Breast Cancer - An Indian Perspective. Acad. J Surg. 2019;2(1):24-27.

DOI: dx.doi.org/10.21276/ajs.2019.2.1.8

Source of Support: Nil, Conflict of Interest: None declared. 